\title{
El sorteo y la sociología de las retribuciones políticas: a propósito de un debate en la Asamblea francesa*
}

\author{
The Sortition and Sociology of the Political Rewards: concerning \\ a Debate in the French Assembly
}

FRANCISCO MANUEL CARBALLO RODRÍGUEZ**

\begin{abstract}
Resumen: En este artículo se plantea el análisis de un debate sobre la introducción del sorteo en política. Presentaremos dos propuestas debatidas en la Asamblea Nacional Francesa en 2015 y las analizaremos movilizando dos marcos teóricos: el primero de ellos es el que desarrolla Bernard Manin en su libro Los principios del gobierno representativo. El segundo, nos permitirá plantear una discusión de los límites del marco anterior, a partir de los conceptos de campo político y capital político. Por último, trataremos de mostrar la utilidad del concepto de capital político para objetivar críticamente el discurso de la representación basado en el principio de distinción.
\end{abstract}

Palabras clave: Manin, sorteo, participación, capital político, retribuciones políticas.

\begin{abstract}
This paper analyses a debate about the introduction of the sortition in politics. We will describe and analyse two proposals discussed in the French Assembly in 2015, drawing from two theoretical frameworks: the first of them, developed by Bernard Manin's The principles of representative government. The second, starting from the concepts of political field and political capital, will allow us to present a debate about the limits of the previous framework. Finally, we will try to show the utility of the concept of political capital to critically objectify the speech of the representation based on the principle of distinction.
\end{abstract}

Keywords: Manin, sortition, participation, political capital, political rewards.

\section{Introducción}

En octubre de 2015, el grupo de trabajo denominado "El futuro de las instituciones" presentó el informe Rehacer la democracia. El grupo fue creado y dirigido por el presidente de la Asamblea Nacional Francesa y estaba formado por once parlamentarios de todos los

Fecha de recepción: 21/09/2016. Fecha de aceptación: 22/01/2017.

* Texto escrito en el marco del proyecto de I+D: "La recepción de la Filosofía grecorromana en la Filosofía y las Ciencias Humanas en Francia y España desde 1980 hasta la actualidad" (FFI2014-53792-R). Agradezco a Jorge Costa Delgado y a José Luis Moreno Pestaña los comentarios que hicieron a la versión de este texto que se discutió en una sesión del seminario de lectura de nuestro grupo de investigación en la Facultad de Filosofía de la Universidad de Cádiz.

** Investigador predoctoral en formación contratado, con cargo al plan propio 2015 de la Universidad de Cádiz, en el Departamento de Historia, Geografía y Filosofía. Líneas de investigación: teoría de la democracia, sociología política y sociología de la filosofía y de los intelectuales. Publicaciones recientes: "Maurice Halbwachs y la estadística en sociología", Encrucijadas, Vol. 13, 2017. "Crise économique et mobilisations pour l'emploi", Savoir/agir, $\mathrm{N}^{\mathrm{o}} 31,2015$. 
grupos políticos y por doce expertos de diversos ámbitos. Para la elaboración del documento con las propuestas, el grupo recurrió a treinta y un especialistas, cada uno de ellos en distintos temas. Cada invitado hizo una exposición y a continuación se debatió con ellos sobre el tema en cuestión. En el informe ${ }^{1}$ que contiene la información que utilizaremos en este artículo, la cuestión del sorteo fue tratada durante la sesión a la que asistió Bernard Manin, quien fue invitado a hablar de la "representación política" e hizo una propuesta para introducir el sorteo en política. Por otra parte, una diputada que formaba parte del equipo de trabajo hizo otra propuesta en la que el sorteo estaba presente.

En este artículo, presentaremos las dos propuestas y las analizaremos movilizando dos marcos teóricos. El primero de ellos es el que desarrolla Bernard Manin en su libro Los principios del gobierno representativo. En esta primera dimensión del análisis, nos centraremos en los debates actuales sobre la democracia, que orientan la posición que defiende Manin. Para una primera aproximación a nuestro objeto de estudio, debemos ordenar los debates actuales sobre la democracia, según la caracterización que de ellos hace Paul Lucardie $(2014,6)$. Retendremos una de ellas, la "escuela clásica", que conserva las definiciones de Platón y Aristóteles, para quienes en democracia las decisiones deben ser tomadas por los ciudadanos. Desde esta lectura, sus herederos modernos lamentan no disponer de formas reales de democracia directa y dejan a un lado la preferencia de los filósofos clásicos, como en el caso de Aristóteles, por los regímenes mixtos. Una excepción en esta escuela es la de Bernard Manin, que se inspira en el modelo de "constitución mixta" de Aristóteles para desarrollar su modelo, aplicable a los sistemas de gobierno representativo que caracteriza a las democracias modernas, como regímenes mixtos. En ellos, Manin identifica cuatro principios que se integran en un sistema equilibrado que hacen emerger la cara democrática de las formas de gobierno representativo en las que se utiliza exclusivamente la elección. Lo veremos detenidamente más adelante.

La propuesta de introducir el sorteo que defendió Manin presenta dos límites importantes que deben destacarse. En primer lugar, su modelo excluye la dimensión de ampliación de la participación política. En segundo lugar, en su argumentación se separa radicalmente del que fue uno de los pilares de las democracias antiguas, la rotación, que su libro ayudó a comprender y a valorizar. En cierto modo, el material que analizaremos nos permitirá pensar a Manin contra Manin, contrastando su posición teórica y su propuesta práctica y su justificación, veinte años después de la publicación de su libro. A continuación, otra propuesta presentada sobre cómo introducir el sorteo en política, esta vez más radical, nos servirá para analizar la resistencias a la aparición de nuevas formas de participación en el campo político.

Para ello, en la segunda dimensión del análisis, plantearemos una discusión de los límites del marco anterior, a partir de los conceptos de campo político y capital político, y de otros asociados a ellos, como el de retribuciones políticas y capital militante, forjados en la sociología de Pierre Bourdieu. Esta perspectiva nos servirá para encuadrar las críticas más agresivas que recibió la segunda propuesta, que procedían de una política profesional y de un dirigente sindical, ambos con amplias trayectorias de militancia. Este marco teórico sobre el campo político nos servirá para completar el esquema conceptual de Manin. Por

1 “Refaire la démocratie". Rapport n. ${ }^{\circ} 3100$ (en linea). http://www2.assemblee-nationale.fr/static/14/institutions/ Rapport_groupe_travail_avenir_institutions_T1.pdf, acceso 16 de febrero de 2016. 
último, trataremos de mostrar cómo el concepto de capital político es útil para: en primer lugar, objetivar críticamente el discurso de la representación basado en el principio de distinción, y en segundo lugar, para ver cómo puede socializarse ese capital y producir más competencias políticas.

\section{La propuesta de Bernard Manin: el sorteo y la crisis del gobierno representativo}

En la sesión a la que fue invitado, a Bernard Manin se le pidió hablar sobre el tema de la representación. Preguntado por los desafíos a los que se enfrentan las democracias modernas, en un momento en el que la representatividad de las instituciones políticas está cuestionada y en el que los ciudadanos exigen más participación, Manin organizó su reflexión en torno a tres puntos. Una buena parte de su intervención y del posterior debate se centró en su propuesta de introducir el sorteo en la selección de grupos para el desarrollo de diferentes tareas vinculadas a la deliberación política. A continuación, nos ocuparemos de su propuesta y, por razones de espacio y de interés para nuestro propósito principal, pasaremos por alto el resto de su intervención.

En primer lugar, hay que decir que el modelo de sorteo que defiende aquí Manin, está limitado a grupos orientados a la deliberación ${ }^{2}$. Manin defiende un uso limitado del sorteo a tareas informativas, llevadas a cabo por ciudadanos "ordinarios", que pudieran orientar las decisiones que deben tomar los representantes elegidos en las urnas. Este uso de las asambleas deliberativas, intuye Manin, reforzaría la legitimidad de la representatividad política, ahora puesta en cuestión, por la vía de la representatividad social. Se trata del último modelo de lógicas políticas que distinguía Sintomer, en el que los grupos deliberativos elegidos por sorteo seleccionan una muestra representativa de la población, un microcosmos de la comunidad que puede opinar, evaluar, juzgar, y eventualmente decidir en nombre de la colectividad, allí donde no todos pueden formar parte de la deliberación y la heterogeneidad social no permite pensar que todos los individuos son intercambiables. El modelo de la muestra representativa presenta algunas características particulares que deben destacarse: 1) Puede ser visto como una imagen instantánea, en miniatura, de la suma de las opiniones de cada uno de los individuos. 2) En él puede verse la diversidad del conjunto de población general del que es seleccionado, lo que favorecería que la deliberación fuese más enriquecedora e igualitaria, puesto que tendría en cuenta más puntos de vista, en función del origen de cada uno de los miembros de dicha muestra. 3) La muestra representativa puede también pensarse como un grupo que representa los intereses de las principales categorías de la población. 4) Puede utilizarse como un medio para poner en valor el juicio de los profanos en relación a los saberes profesionales. 5) Por último, puede utilizarse como técnica para movilizar a ciudadanos ordinarios cuando otros modos de selección de participantes voluntarios no funcionen (Sintomer, 2011). Este mecanismo ayudaría a mejorar la credibilidad y la confianza en las instituciones. En términos operativos, las asambleas sorteadas estarían asesoradas por expertos del tema a tratar y por lo tanto sometidas a un intenso proceso de

2 El grupo deliberativo elegido por sorteo que defiende aquí Manin, pertenece a uno de los modelos tipificados por Yves Sintomer (2011) quien, a partir del análisis sociológico e histórico de un conjunto de experiencias en las que se ha utilizado la selección aleatoria en política, distingue cinco tipos ideales en función de sus diferentes lógicas políticas. 
aprendizaje. Manin insiste en repetidas ocasiones sobre esta dimensión del aprendizaje y explica que en ella reposa la diferencia fundamental entre una asamblea sorteada entre ciudadanos "ordinarios" (se refiere con esto, a que no son especialistas de ninguna materia, ni políticos profesionales o militantes) y un grupo de personas que discuten, organizados por ejemplo, en torno a un grupo político o cualquier otro de carácter más o menos informal. La primera objeción al modelo que propone Manin, la hizo Alain Tourret. Este diputado de la Asamblea Nacional del "Grupo Radical, Republicano, Demócrata y Progresista”, de centroizquierda, recurre a su condición de abogado y a su experiencia con los jurados populares sorteados para argumentar que los ciudadanos que los componen suelen inclinarse hacia la defensa del orden, dando pocas pruebas de humanidad y comportándose en sus decisiones de un modo extremadamente severo. Esta objeción sirve para que Manin retome de nuevo la cuestión del aprendizaje. Argumenta que las experiencias que se conocen demuestran que estos grupos, tras haber sido informados por expertos desde ópticas contradictorias, tienen tendencia a moderar sus opiniones finales con respecto a las que tenían antes del comienzo de la deliberación. Conviene señalar en este momento, que Manin no entiende las asambleas sorteadas como mecanismos de participación. A su parecer, la lógica de la participación es muy distinta y considera que favorecerla debe continuar siendo una tarea de la que se ocupen los partidos políticos u otros grupos organizados, en función de sus intereses legítimos. En el desarrollo de la sesión, algunos de los miembros del grupo de trabajo mostraban sus recelos ante la idea del sorteo argumentando que un grupo elegido al azar, y por lo tanto de manera aleatoria, no reflejaría la verdadera dimensión de la relación de fuerzas antagónicas presentes socialmente. Esta distorsión, explican, tendería a ocultar relaciones de dominación que la composición proporcional de las cámaras, en un principio y de manera ideal, sí deberían reflejar. Los defensores de este argumento, reconocen al mismo tiempo, que los partidos de masas han sufrido un proceso de cierre y que han limitado mucho la posibilidad de participar a un gran número de personas. No obstante algunos, a modo de alternativa, sugieren mecanismos como los que posibilitan las nuevas tecnologías (teléfonos móviles, internet) para desarrollar procesos de debate participativos. En respuesta a estas apreciaciones, Manin insiste en su idea de que las distintas formas de participación política son compatibles con la existencia de las asambleas sorteadas, puesto que ofrecen resultados muy diferentes. A propósito de la primera objeción, sobre la relación de fuerzas, explica que los grupos sorteados están compuestos, de manera ideal, por personas que no se conocen y que son convocadas para deliberar y consensuar una opinión sobre un tema concreto. Se trata pues de razonar, utilizando argumentos, a partir de las informaciones que se van acumulando y de los juicios que se forman en el transcurso de los debates. No existe una lógica de confrontación partidista o ideológica. En el caso del recurso a las nuevas tecnologías, Manin advierte que los grupos se movilizan siguiendo criterios de afinidad y que por lo tanto, las diferencias, en cuanto a las opiniones, suelen ser mínimas. Otro problema añadido es que esos grupos tienen un acceso muy limitado a la información, o más bien, recurren a informaciones que son bien valoradas por la mayoría. En un grupo sorteado, por el contrario, sus miembros tienen a su alcance información que no tendrían en un círculo de su elección. Para acabar con la cuestión de la participación, Manin explica de qué modo el sorteo puede ser útil, incluso si se utiliza de manera complementaria a uno de los mecanismos más defendidos para la participación, el referéndum. Para ello hace referencia al estado de Oregón, en Estados Unidos, donde hacen 
uso del referéndum a instancia de los ciudadanos de manera frecuente. En este caso, una asamblea sorteada delibera sobre el tema del que trate la consulta y el informe que emiten se envía por correo postal junto con el resto de la propaganda electoral.

Manin considera a las democracias representativas como sistemas imperfectos que se encuentran constantemente en crisis. La introducción del sorteo, como mecanismo de deliberación disponible para ciudadanos "ordinarios" que tienen la oportunidad de opinar sobre temas concretos, con carácter meramente consultivo, reforzaría la dimensión de la responsabilidad de los representantes electos. En este sentido, Manin defiende que esa sería una herramienta útil para la necesaria rendición de cuentas. En la medida en que los resultados de la deliberación se hiciesen públicos, los cargos electos deberían justificar sus decisiones. Ciertamente, tal vez fuese más difícil explicar las razones por las que se adoptan unas u otras medidas, a favor o en contra, pero esa obligación de claridad reforzaría la legitimidad, ahora muy erosionada, de los representantes frente a los representados.

Pero el sorteo no era la única institución fundamental sobre la que reposaban los principios de la democracia ateniense, de hecho, no se entendería de no estar unida a la rendición de cuentas y, fundamentalmente, a la rotación en los cargos. Pues bien, uno de esos elementos también estuvo presente: sobre la rotación de cargos también se discutió en este grupo de trabajo. Concretamente, sus miembros estaban interesados en la cuestión de la limitación de mandatos. En este punto, Manin defiende la importancia de la continuidad de los proyectos políticos y la pone en relación con la responsabilidad, y por lo tanto, con la rendición de cuentas. Manin no excluye la posibilidad de limitar el tiempo durante el que un dirigente puede permanecer en un cargo, pero sí señala que la continuidad es lo que permite que un proyecto político se someta, a largo plazo, a la sanción de los ciudadanos en las urnas. En este sentido, Manin identifica en los políticos una suerte de irresponsabilidad, "una miopía estructural", que hace que tiendan a pensar a corto plazo. A su juicio, el compromiso de permanencia de un proyecto político (no debemos pensar solo en personas) a largo plazo es lo que hará que sus dirigentes se comporten de manera responsable. Manin, de ese modo, se separa radicalmente de uno de los pilares de las democracias antiguas, que precisamente su libro ayudó a comprender y valorizar. Lo vemos en lo que sigue.

\section{Rasgos democráticos y oligárquicos de los sistemas de gobierno representativo}

No cabe duda, de que hay que atribuir a Manin el mérito de haber ordenado el debate de los últimos veinte años, desde la fecha de la primera publicación de Los principios del gobierno representativo en 1995, sobre la evolución de los distintos sistemas de gobierno y de la imposición de la elección y el olvido del sorteo como herramienta de selección de cargos políticos.

No obstante, cabe repensar, aunque sea limitadamente, a Manin contra Manin. Porque tal vez, en la participación efectiva de los ciudadanos en las instituciones se encuentren mejores soluciones, más democráticas y más duraderas a problemas como el de la legitimidad o la responsabilidad de los representantes políticos. Todo eso nos lo enseña la experiencia de las democracias antiguas, concretamente la ateniense, donde la responsabilidad del gobierno era compartida, a un nivel que hoy nos resulta difícil de entender. "Se ha señalado a menudo -escribe Manin- que la rotación reflejaba una visión de la vida en la que la actividad política 
y la participación en el gobierno eran las más elevadas formas de excelencia humana, pero alternar mando y obediencia era también un mecanismo para conseguir un buen gobierno. Estaba pensado para producir decisiones políticas acordes con cierto sentido de la justicia, la justicia democrática" (Manin, 1998, 44). La capacidad de los ciudadanos, tanto para ser gobernados como para gobernar, definía el principio fundamental de la rotación y justificaba el uso del sorteo del que hacía que fuese "una solución racional: como en cualquier caso un número substancial de ciudadanos ocupaban cargos, un día u otro, se podía dejar en manos del azar el orden de su acceso a los mismos" (Manin, 1998, 46). La rotación y el sorteo situaba a los ciudadanos en condiciones de igualdad para enfrentarse a las tareas de gobierno, y esto era algo central, puesto que servía para prevenirse de la profunda desconfianza que inspiraba el profesionalismo a los atenienses (Manin, 1998, 47).

En las formas modernas de gobierno, Manin identifica cuatro principios que se integran en un sistema equilibrado que hacen emerger la cara democrática de las formas de gobierno representativo en las que se utiliza exclusivamente la elección. Esos cuatro principios identificados por Manin $(1998,17)$ son: en primer lugar, que quienes gobiernan son nombrados por elección a intervalos regulares. En segundo lugar, que la toma de decisiones por los que gobiernan conserva un grado de independencia respecto de los deseos del electorado. En tercer lugar, que los que son gobernados pueden expresar sus opiniones y deseos políticos sin estar sujetos al control de los que gobiernan. Por último, que las decisiones públicas se someten a un proceso de debate. Estos principios, serían reconocibles en tres tipos de gobierno representativo, que Manin esquematiza en tres tipos ideales: parlamentarismo, democracia de partidos y democracia de audiencia (Manin, 1998, 247). Como tipos ideales que son, cada uno de los modelos no se corresponde con un momento en la historia del sistema de gobierno representativo. De hecho, podría decirse que cada una de las caracterizaciones añade nuevos elementos a la anterior, de modo que no puede constatarse una mutación total pero sí variaciones en función del momento.

Manin identifica la capacidad de resistencia de los sistemas de gobierno representativo, en tanto que regímenes mixtos, inspirándose en la idea de constitución mixta de Aristóteles ${ }^{3}$, que se equilibran combinando ambas dimensiones: la democrática y la oligárquica (Manin, 1998, 289-292). En el mundo antiguo, la elección tenía un carácter aristocrático ${ }^{4}$, pero su poder estaba limitado y corregido por el uso del sorteo, que tenía un carácter democrático. "El escritor griego Polibio, que vivió en Roma en el siglo II a.C., no presenta el sistema político romano

3 "Pensaba Aristóteles que, sintetizando arreglos democráticos y oligárquicos, se obtenía una mejor constitución que con un régimen puro. Diversas combinaciones entre sorteo, elección y adecuada formación permitían ese tipo de síntesis [...] Se puede, por ejemplo, decidir que las magistraturas deban ser electivas (más que asignadas por sorteo), pero que cualquiera, independientemente de si está bien cualificado para ello, se pueda presentar o votar en las elecciones o ambas cosas. Otra combinación puede consistir en asignar cargos por sorteo pero sólo entre ciudadanos caracterizados por tener la cualificación adecuada. O ciertos cargos se pueden cubrir con elección y otros por sorteo. Según el filósofo, esas diferentes combinaciones producen constituciones oligárquicas en ciertos aspectos y democráticas en otros. Para Aristóteles, entonces, la elección no era incompatible con la democracia, pero tomado aisladamente es un método oligárquico o aristocrático, mientras que el sorteo es intrínsecamente democrático" (Manin, 1998, 42).

4 En la antigua Grecia, "la idea de representación está por completo ausente de la filosofía y la práctica [...] cuando hay elección, nadie habla de los elegidos como "representantes" -son magistrados, algo muy diferente-, porque no representan a nadie y, por añadidura, el principio de la elección se considera aristocrático" (Castoriadis, 2012, 110). 
como una democracia sino como una constitución mixta. El gobierno de Roma, argumenta Polibio, era una combinación de características monárquicas, aristocráticas y democráticas" (Manin, 1998, 62). A partir de esta definición, pero dejando a un lado la dimensión monárquica, nos dice Manin, "la elección puede calificarse, por analogía, como una institución mixta" (Manin, 1998, 192). Para nuestro autor, por lo tanto, la dimensión aristocrática y la democrática "son objetivamente verdaderas [...] Ambas dimensiones no sólo son igual de reales; son inseparables [...] Sus dos propiedades están tan férreamente entrelazadas que posiblemente no puedan escindirse una de la otra. Ni las élites ni los ciudadanos corrientes están en posición de retener la propiedad que les es favorable, ni de deshacerse de la otra, ya que ninguna de las dimensiones está encarnada en una institución distinta. Además, las propiedades igualitarias y no igualitarias, al constituir las dos caras de una única e indisoluble operación, permiten percibir el procedimiento electivo como completamente democrático o como completamente aristocrático dependiendo de cómo se mire" (Manin, 1998, 192-193).

Para Manin por tanto, el carácter oligárquico del gobierno representativo revela, en la práctica, una relación compleja entre los ciudadanos y las elites políticas, todo ello en un marco democrático. Y lo justifica así: “para mí, las élites juegan, en efecto, un papel importante en el gobierno representativo. Esto es así, porque las elecciones seleccionan necesariamente a individuos dotados de características poco comunes, que son valoradas de manera positiva por los electores [...] Los electores eligen las cualidades distintivas que quieren encontrar en sus representantes". El principio normativo defendido por Manin, reposa sobre la idea de que el poder político emana "del consentimiento libre de aquellos sobre los que se ejerce". Así, resume Manin, "mi argumento sobre las élites es positivo, no normativo. Puede reconocerse la importancia, de hecho, de las élites sin tomar partido por el elitismo como valor [...] Una perspectiva normativa más ambiciosa precisaría de una larga y compleja argumentación, teniendo en cuenta la estrecha relación de las dimensiones igualitarias y no igualitarias de la representación" (Landemore, 2008).

Vemos con claridad que Manin, mediante su propuesta, habiendo identificado los problemas de la representación en las democracias modernas, no se cuestiona cómo incentivar la voluntad de participar de los agentes, sino que se centra en los problemas que atraviesan a las organizaciones políticas y a las instituciones. Por ello, podemos insistir en que la propuesta de introducir el sorteo en política que defiende trata de legitimar los sistemas representativos tal y como los conocemos.

\section{El sorteo y la entrada de ciudadanos ordinarios en política}

Bernard Manin hace una propuesta de utilización del sorteo en la que descarta la entrada de ciudadanos ordinarios en las cámaras de representación y que por lo tanto, se aleja de los principios de responsabilidad compartida de los ciudadanos en las tareas de gobierno, sobre los que descansaban la rotación y el sorteo (ser gobernados sabiendo que un día se podrá gobernar) en la democracia ateniense. Pese a ello, el uso del sorteo que plantea no cabe duda de que aumentaría la calidad democrática de las decisiones de los representantes políticos, al menos de manera ideal.

Otra propuesta, esta vez más radical, integra esos dos principios orientadores del buen gobierno, basados en la rotación y el sorteo como instrumentos para la selección de repre- 
sentantes políticos. La hizo una diputada del Partido Socialista, Karine Berger. Su propuesta contempla dos posibilidades. La primera consistiría en reformar el Senado para convertirlo en una cámara de representación territorial donde estuviesen proporcionalmente integradas cada una de las trece regiones francesas, con el fin de avanzar hacia un diseño de República federal similar al modelo alemán. En esa cámara reformada, una parte de sus miembros serían elegidos por sorteo entre los ciudadanos. La segunda posibilidad de integrar a ciudadanos "ordinarios" en el sistema representativo, consistiría en seleccionar por sorteo a los miembros de un "Consejo económico y social" reformado, de modo que el sistema representativo pasase de ser bicameral a un modelo compuesto por tres cámaras. En ambos casos, los representantes seleccionados por sorteo se irían renovando periódicamente. De la autora de esta propuesta debe destacarse que además de diputada de la Asamblea Nacional, es una alta funcionaria del Estado, concretamente del INSEE (Instituto nacional de estadística y de estudios económicos) y que como militante y dirigente del Partido Socialista, ha ocupado numerosos puestos de responsabilidad. Por otra parte, al mismo tiempo que este grupo de trabajo debatía en la Asamblea Nacional, Karine Berger encabezaba la lista de un conjunto de militantes socialistas, miembros de la corriente "Coherencia Socialista" que preparaban un documento de propuestas y de organización alternativo, para el Congreso ordinario que el Partido Socialista celebró en junio de 2015 en Poitiers. El documento, denominado "La

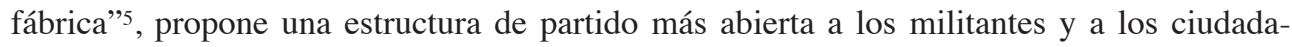
nos en general y se compromete, de ser aceptada por la mayoría, a sortear una "Asamblea ciudadana", de entre todos sus militantes, para abordar los debates de sus líneas políticas. La propuesta de Karine Berger fue considerada y en el cuestionario que serviría de base para la redacción de las recomendaciones, se incluyó una pregunta que expresamente hacía referencia al uso del sorteo, en una eventual reforma del Senado. Esta posibilidad suscitó dos respuestas muy claras en su contra. La primera, por parte de Cécile Duflot, diputada y presidenta del Grupo Ecologista en la Asamblea Nacional, y la segunda, por parte de Bernard Thibault, el histórico secretario general del sindicato CGT (Confederación General del Trabajo) y en la actualidad miembro de la OIT (Organización Internacional del Trabajo). En ambos casos, el rechazo reposa en argumentos muy similares, según los cuales, no debe dejarse al azar la selección de personas que deberán desarrollar un trabajo político de representación de los intereses generales. Dicho de otro modo, puesto que las decisiones políticas afectan a colectivos, no pueden dejarse en manos de individuos que solo se representan a sí mismos. Así, aquellos a quienes se les asignen tareas políticas deben ser elegidos entre los miembros de colectivos que defiendan intereses en torno a una causa. En todo caso, las instituciones políticas deben abrirse a la participación de grupos sociales organizados. Abiertamente contrarios a abrir las instituciones políticas a los ciudadanos "ordinarios", fuera del marco de grupos organizados, ambos son favorables, sin embargo, a explorar las posibilidades del uso del sorteo para la selección de miembros de grupos deliberativos, según la anterior propuesta de Bernard Manin.

En la propuesta de Karine Berger, vemos que incluir a "profanos" en las cámaras de representación junto a los "profesionales" de la política, rompe con el monopolio de los

5 Documento disponible en linea: http://congres.parti-socialiste.fr/motions/motion-d-la-fabrique.pdf, acceso 19 de abril de 2016. 
partidos en las vías de acceso, legítimas, al poder político pero que sin duda merecen reconsiderarse. Si se asume que las tareas políticas pueden y deben ser ejercidas por cualquier ciudadano, que a su vez reconocerá en el ejercicio del gobierno de los demás el mismo principio de legitimidad basado en la igualdad de competencias políticas ${ }^{6}$, podemos pensar que la cuestión de la crisis de legitimidad se vería desplazada hacía el cuestionamiento de las formas de entrada en la política institucional, ahora únicas, vía elección y progreso en el cursus honorum de acumulación del capital político. Se trata, en definitiva, de constatar que "en la sociedad moderna, en todo aparato burocrático jerárquico, incluidos por supuesto los partidos políticos, el individuo que quiere llegar a la cima debe recorrer los escalones de la pirámide burocrática; este ascenso mismo se convertirá, por la fuerza de las circunstancias, en su única preocupación. Y tendrá cada vez menos que ver con su capacidad de llevar a cabo las tareas que supuestamente debe cumplir, y cada vez más con su lisa y llana capacidad de trepar" (Castoriadis, 2012, 115). Por lo que exigiría aún otro esfuerzo, esta vez en el interior de las organizaciones políticas, que deberían reflexionar sobre sus formas de gobierno y de selección de cuadros, de dirigentes y de candidatos. Estas dos cuestiones están presentes en la propuesta de la diputada socialista. La primera cuando sugiere que una parte del senado sea elegido por sorteo, la segunda, en el seno de su organización cuando propone sortear entre sus militantes a aquellos que deberán decidir qué líneas políticas se adoptarán. El principio que inspira ambas posiciones, no parece otro que el de profundizar en los procesos democráticos, favoreciendo la implicación de un número elevado de ciudadanos en la toma de decisiones. El alcance de las medidas que propone Karine Berger puede medirse por las reacciones que provocó e incluso por las posiciones que tales posibilidades inspiran. En este sentido y en un plano abstracto, reflexionando sobre las posibilidades de ampliar la democracia en las instituciones, la socióloga Dominique Schnapper manifestó que el sorteo plantea un problema sobre las competencias de quienes deben tomar decisiones políticas, al ser considerados en un plano de igualdad. El problema de distinguir competencias políticas y competencias técnicas, que los atenienses conocían bien, sigue instalado en nuestro horizonte de lo posible y de lo pensable en política. En Atenas, aquellas funciones que requerían de competencias técnicas específicas, eran ejercidas por cargos elegidos y no sorteados, como era el caso en algunas magistraturas. Pero en el mismo sentido, su crítica no fue la única. Para el profesor de derecho Denis Baranger, las ventajas del uso del sorteo son inciertas. Por un lado, cuestiona que pudiese mejorar la representatividad, haciéndola más racional y legitimándola, por otro, duda de que sirviese para mejorar las instituciones en términos democráticos. En ambos casos cree que existe el riesgo de que los ciudadanos ordinarios, al situarse en el mismo plano que los profesionales de la política, sufran el mismo descrédito que ellos. Pero la crítica más dura de este profesor se dirige hacia la calidad de las decisiones que se adopten, en función de que procedan de un experto o de alguien seleccionado al azar, "tirando unos dados". Si las reticencias de Dominique Schnapper y de Denis Baranger se fundamentan en presupuestos difícilmente demostrables, las de Jean-Noël Jeanneney, historiador y antiguo Secretario de Estado del gobierno de François Mitterrand

6 El principio de igualdad de competencias políticas, es radicalmente democrático, "pues la democracia supone que todos los ciudadanos tiene la posibilidad de alcanzar una doxa correcta y que nadie posee una episteme de las cosas políticas" (Castoriadis, 2005, 116). 
reposan en argumentos sobradamente discutidos. El que fuese director de la Biblioteca Nacional de Francia hasta 2007, dice que la Grecia antigua no puede servir como ejemplo de nada, puesto que su democracia solo se entendía por la esclavitud, que era la institución que aseguraba las condiciones de la vida cotidiana de los ciudadanos. Sobre esto, Castoriadis ha argumentado convincentemente que la esclavitud ha existido en muchos lugares pero la democracia solo en las polis griegas. Por otra parte, también nos muestra que en dichas polis, la esclavitud no fue ni una condición suficiente ni tampoco necesaria (Castoriadis, 2012, 49-51, 72-80).

Hemos descrito dos formas diferentes de introducir el sorteo en sistemas de gobierno actuales y cómo ambas se plantean el objetivo de mejorar su calidad. Por otra parte, las críticas revelan, que las modificaciones que mayoritariamente se admiten para renovar un sistema del que se dice que está en crisis, están muy cerca de la visión dominante del campo político. En el material que utilizamos aquí, podemos ver cómo se mezclan los argumentos que proceden de visiones más objetivistas, o científicas si se quiere, con otros que lo hacen de visiones con un carácter más espontáneo o militante. Tanto en unos como en otros, la cuestión central de la crisis de representación aparece como el resultado de un cierto estado de cosas, relativamente estable.

\section{Algunas reglas del campo político y condiciones para la participación: una perspectiva sociológica}

En diferentes momentos de este texto, hemos visto ejemplos de las dificultades a las que se enfrenta el sistema de gobierno representativo. Por una parte, los ciudadanos perciben a los políticos como a un grupo cerrado sobre sí mismo, que trabaja más por sus intereses (los propios y los de sus organizaciones) que por los de aquellos a quienes representan. Por otra parte, los partidos son conscientes de que han experimentado cambios internos que los han alejado de los ciudadanos. Hasta ahora nos hemos ocupado del funcionamiento de las instituciones políticas, de sus problemas de funcionamiento y de su legitimidad. Las propuestas que hemos presentado tratan de ofrecer salidas democráticas a esos problemas, recurriendo a instituciones del pasado que pueden ser recuperadas con imaginación, aunque también -hemos visto- con muchas dificultades, para poner de acuerdo a un amplio número de personas. Pero al ocuparnos del funcionamiento de las instituciones, ocultamos una parte fundamental de la cuestión que tratamos de aclarar. Se trata de preguntarse acerca las razones por las que las personas están dispuestas a invertir tiempo y esfuerzo en el trabajo político. Habitualmente, la respuesta que suscita un mayor consenso, tanto entre los militantes como entre los analistas, es la que nos remite a razones ideológicas. Asumir esta explicación, implica aceptar la visión de sí mismo, que produce e impone una región del mundo social, la del campo político, que de ese modo legitima las condiciones de acumulación, nos explica Bourdieu (1988), "de esa especie particular de capital simbólico que es el capital político". Tanto si se trata de beneficios materiales (un trabajo o un salario) como simbólicos (el honor o la reputación), la participación política proporciona bienes. Preguntarnos por las condiciones sociales en las que se produce ese intercambio, nos parece necesario para comprender un poco más algunas de las cuestiones que este debate sobre el sorteo nos proporciona. Pese a que este marco de análisis no está 
presente en el trabajo de Manin, en sus reflexiones, a propósito de los debates y a partir del conocimiento de experiencias concretas, veremos cómo aparecen y en qué medida refuerzan los argumentos para una defensa del uso del sorteo en política.

En una definición amplia de la política, Max Weber nos dice que es "la aspiración a participar en el poder o a influir en la distribución del poder entre los distintos Estados o, dentro de un mismo Estado, entre los distintos grupos de hombres que lo componen". La política pues, como medio para alcanzar el poder y que quienes aspiran a él, lo utilizan "como medio para la consecución de otros fines (idealistas o egoístas) o al poder "por el poder', para gozar del sentimiento de prestigio que él confiere" (Weber, 1967, 85). Según lo anterior, las estrategias de los dirigentes políticos y de sus organizaciones están orientadas a ocupar puestos de poder. Con ese objetivo, compatible con la defensa de los intereses de un grupo o la defensa de una ideología, los dirigentes políticos se acaban, en la mayoría de los acasos, profesionalizando. Así, "hay dos formas de hacer de la política una profesión. O se vive «para» la política o se vive «de» la política. La oposición no es en absoluto excluyente. Por el contrario, generalmente se hacen las dos cosas, al menos idealmente; y, en la mayoría de los casos, también materialmente" (Weber, 1967, 95). Robert Michels (1914), por su parte, en su conocida obra sobre los partidos políticos, muestra de qué modo en el seno de las organizaciones políticas, cuando estas tienden a crecer y necesitan fortalecerse, se instala una burocracia cada vez más jerarquizada y una creciente tendencia a la oligarquía que acaba dejando el poder de la organización y la posibilidad de acceso a los cargos públicos en un grupo muy reducido de personas. Esta "ley de hierro de la oligarquía" obliga, además, a la profesionalización de los dirigentes, para los cuáles las necesidades de una organización sólida y compleja exige una dedicación exclusiva. Así pues, el partido político es la herramienta para la obtención del poder institucional. Pero además, es también el medio a través del cual se organiza una forma de participación política mediante el recurso a la acción colectiva. Esta segunda dimensión es la que dota de sentido y legitima a una organización que aspira a representar los intereses de un número importante de personas. Ambas dimensiones, la profesionalización y la utilidad las organizaciones como herramientas de organización de la acción colectiva, las hemos visto reflejadas en las posiciones que mantenían dos dirigentes, la diputada Cécile Duflot y el líder sindical Bernard Thibault, respecto del recurso al sorteo.

Constatando la tendencia oligárquica de las cúpulas de los partidos, Daniel Gaxie desarrolla la noción de retribuciones de la militancia, con la que pretende cuestionar los análisis que se limitan a explicar la militancia por cuestiones de carácter ideológico. Los beneficios que pueden extraerse de la militancia son utilizados por Gaxie como una categoría para el análisis sociológico. Esto es posible, puesto que se presentan empíricamente como una realidad social para un observador atento, sin prejuicios partidistas. Cuando nos referimos a las retribuciones a las que se accede mediante la militancia en un partido político, pensamos de forma inmediata en puestos en las instituciones. Como ya vimos, la empresa weberiana de proveer de poder, y por lo tanto de puestos a sus dirigentes, mantiene su vigencia. En este sentido, conviene aclarar que las ventajas materiales a las que se puede acceder mediante la militancia partidista, están estrechamente unidas al logro de gratificaciones simbólicas (prestigio, honor, poder). Parece lógico pues, que la posibilidad de acceder a este tipo de puestos, resulte lo suficientemente atractiva como para 
que ciertos agentes sociales inviertan una parte importante, cuando no el máximo de sus esfuerzos en el partido. Además de los puestos que acumulan mayor poder, los partidos tienen reservados un número muy importante de posiciones en todos los niveles de las administraciones e incluso en las empresas de carácter público. Pero el capital político que se acumula militando en un partido puede generar satisfacciones distintas a las materiales. Las retribuciones simbólicas que pueden lograrse militando en un partido son muchas y muy variadas. De todas ellas puede decirse que crean "un interés en la militancia" (Gaxie, 1977, 130). De hecho, para considerar la verdadera dimensión del compromiso que se establece en el interior de una organización, seríamos más precisos si hablásemos de capital militante. Este tipo de capital, que se distingue del político, se caracteriza porque se acumula en el mismo campo político en forma de conocimientos prácticos que permitan llevar a cabo tareas y que podrán movilizarse en el desarrollo de las acciones propias de las organizaciones. Una característica de este tipo de capital es que puede exportarse a otros universos e incluso reconvertirse en caso de salida (Matonti y Poupeau, 2004/5). Las retribuciones de orden simbólico son imprescindibles para comprender el orden interno de los partidos y sus jerarquías. Así, los partidos tratan de establecer un sistema de puestos donde las retribuciones simbólicas sean desiguales. Esa escala creciente permite desarrollar un sistema de promoción interna donde las responsabilidades en la organización y las retribuciones aumenten a medida que los militantes intensifican su actividad o acumulan tiempo de permanencia. En este sentido, los partidos desarrollan planes de promoción interna para sus cuadros, del mismo modo que lo hacen las empresas o la administración. Los mecanismos que ayudan a ascender en la jerarquía y los incentivos que se obtienen, refuerzan el compromiso de los militantes más activos. Pero los esfuerzos por mantener el compromiso de los más ambiciosos, tienen casi siempre un efecto no deseado. Al aumentar las retribuciones asociadas a los puestos más altos de la jerarquía, pierden valor las posiciones inferiores y con ello se desincentiva la permanencia en la base de la organización. Este efecto explica una buena parte de las razones por las que los adherentes y los militantes abandonan una organización, o al menos, ofrece una explicación convincente de ese hecho, sin necesidad de recurrir a argumentos que justifican la disminución de efectivos por razones de tomas de posición ideológica u otros factores similares. Otra posibilidad para resolver este efecto indeseado de la jerarquía, que se ve limitada en su capacidad para incentivar mediante cargos de gestión interna el compromiso de sus militantes, es la de multiplicar los niveles de responsabilidad y con ellos el número de responsables (Gaxie, 1977, 130-135). Las satisfacciones que se derivan de la pertenencia a instancias de decisión, incluso en partidos muy pequeños y sin posibilidad real de acceder al poder, explicarían su existencia y confirmarían que ese tipo de retribución simbólica es una condición para el funcionamiento de las organizaciones políticas (Gaxie, 1977, 135). Tanto si se trata de empleos remunerados, de puestos en la jerarquía sin compensación económica, o de satisfacciones del orden de lo simbólico como el honor o el prestigio, en todos los casos, hemos visto cómo las retribuciones que se logran mediante la militancia en una organización política, ofrecen explicaciones convincentes sobre las razones por las que los agentes están dispuestos a invertir su tiempo y su esfuerzo en una empresa colectiva. Considerar esta posibilidad no significa negar la existencia de razones ideológicas. Tampoco quiere decir que ambas motivaciones no puedan darse de forma conjunta. Tan sólo 
se trata de recordar que el compromiso con una causa no puede ser considerado como el único, ni como el elemento determinante de la movilización política o del deseo de participar (Gaxie, 1977, 126).

\section{Conclusiones}

Considerando lo que nos muestra un análisis más detallado del campo político, puede verse cómo la lógica de funcionamiento que produce se refleja en las posiciones que defienden quienes lo integran. Lo hemos visto en las resistencias de la diputada ecologista, Cécile Duflot y de un dirigente sindical, Bernard Thibault, para admitir la posibilidad de seleccionar por sorteo a una parte de los representantes políticos. Aunque esas resistencias pueden sin duda vencerse y la prueba la encontramos en la propuesta de la diputada socialista Karine Berger. Nos hallamos ante un caso en el que una organización política, o una parte de ella, pretende desarrollar mecanismos que posibiliten la "socialización del capital político" , tanto en el interior de la organización como en su relación con el resto de organizaciones y los ciudadanos, en las instituciones. Porque en lo relativo a la participación, para la que Manin reserva las instancias de organización política no institucionales, podemos preguntarnos porqué, cuando se tiene la posibilidad de participar fuera de ellas, en los casos en los que los ciudadanos son elegidos por sorteo para formar parte de asambleas deliberativas, las tasas de rechazo a hacerlo son tan elevadas ${ }^{8}$. Una posible explicación, a modo de hipótesis, puede elaborarse si nos preguntamos por los incentivos que los ciudadanos tienen para participar. Es cierto que en el modelo propuesto por Manin, los grupos sorteados tienen la capacidad de emitir un informe público que, cabe suponer, tendrá algún efecto en el funcionamiento de las instituciones y en sus miembros. De la pertenencia a una instancia de ese tipo, podemos suponer que sus integrantes obtendrán satisfacciones simbólicas, siempre difíciles de objetivar, pero en ningún caso materiales. Por otra parte, sabemos que la legitimidad para ocuparse de determinadas cuestiones, o simplemente para opinar sobre ellas, está distribuida socialmente de forma muy desigual. Si pensamos por ejemplo, en un grupo sorteado que se organiza para deliberar y emitir un informe sobre, pongamos por caso, el modelo energético por el que debe apostar un país, no resulta difícil pensar que la autopercepción de tener algo que aportar al debate no sea la misma, en los casos de un obrero de la construcción, de un profesor universitario o de un agricultor. Parece evidente que las diferencias de capital cultural, de grado de movilización política o de nivel de información, determinarán la decisión de formar parte o no. Habría que determinar también, en cada una de esas experiencias, en qué medida otros muchos condicionantes materiales, económicos o sociales, determinan la disposición a participar. Podemos pensar en los problemas de conciliación de la vida familiar y laboral, en las tareas de crianza de los hijos, en las condiciones de trabajadores precarios sin demasiado tiempo libre, etc. Para todos ellos, se pueden diseñar medidas que compensen

7 La expresión, utilizada por José Luis Moreno Pestaña (2015), hace referencia al principio “socialista”, que introduciría el uso del sorteo, mediante un proceso de aproximación de los profanos y los profesionales de la política, limitando los mecanismos de acumulación de capital político en el caso de los segundos y ampliándolos en el caso de los primeros.

8 Manin explica que en numerosas experiencias donde se hace un uso intensivo del sorteo, como en el caso de la región italiana de la Toscana, la tasa de rechazo a participar supera el $90 \%$. 
dichas dificultades, y tal vez de ese modo, se pudiera valorar de nuevo el nivel de rechazo y sus causas. Pero recordemos también, que de las experiencias que se conocen podemos extraer algunas ideas de mucha utilidad. Insistía Manin, en su intervención sobre el sorteo, en la dimensión del aprendizaje en el funcionamiento de los grupos deliberativos sorteados. Puesto que lo que se produce en esos grupos, es un proceso de aprendizaje y por lo tanto de acumulación de capital cultural, sea cual sea el nivel de formación y de información inicial de cada uno de los miembros; en esencia, los procesos que desembocan en la toma de decisiones, tanto si no son vinculantes como cuando sí lo son, en el caso de los representantes políticos, podemos pensar que son similares. ¿Acaso los representantes políticos no se forman para el desempeño de sus tareas al mismo tiempo que las desarrollan?, ¿no están, ellos también, sometidos a un proceso de aprendizaje, informados por expertos de la materia sobre la que deben decidir? Las preguntas nos remiten a las objeciones que se hicieron a la propuesta de la diputada socialista y a su idea de sortear a una parte de las cámaras de representantes. Recordemos que se decía que las competencias de quienes son elegidos como representantes determinaban la calidad de sus decisiones, y se cuestionaba la posibilidad de considerar como iguales las que eran tomadas por especialistas o por quienes no lo eran.

Estábamos en el terreno del debate sobre las competencias técnicas y las competencias políticas. Retomemos el ejemplo del grupo que delibera sobre el modelo energético que debe adoptar un país. Cuando un debate como este se produce en un parlamento, en el conjunto de representantes elegidos en las urnas no todos son especialistas. De hecho, puede ocurrir que ninguno de ellos lo sea. Pese a ello, la decisión que se adopte, sea en el sentido que sea, se ajustará a los límites técnicos que el conocimiento en la materia nos proporcione. Lo que determinará el sentido "político" -ideológico si se quiere- de la decisión, estará orientado por otras razones que habrá que determinar. Por lo tanto, la calidad de las decisiones políticas tiene poco que ver con la especialización. No ocurre lo mismo, por descontado, con la calidad de las decisiones técnicas. Pero volvamos a la cuestión del aprendizaje como proceso y a su importancia en el trabajo político. En un momento del debate con Bernard Manin, se abordó la cuestión de la acumulación de mandatos. Ya vimos que Manin defiende al respecto la continuidad de los cargos políticos y de sus proyectos, lo que reforzaría a su juicio, la responsabilidad de los mismos y la posibilidad de los electores de someterlos a examen en cada nueva convocatoria electoral. De ese modo, entiende Manin, los representantes rinden cuentas de su trabajo ante los ciudadanos. Para que lo anterior sea posible, Manin argumenta que es necesario que los representantes conozcan su "oficio". Sobre esto dice: "la calidad de la renovación -en los cargos electos- depende de la continuidad: son los viejos quienes enseñan a los nuevos cómo funciona una asamblea, quienes los socializan y les permiten ir subiendo escalones. De ese modo se aprende el oficio, ¡una vez elegido!

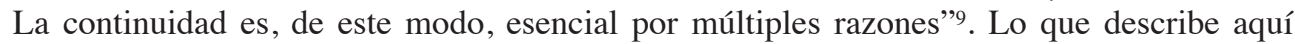
Manin son las condiciones necesarias para la transmisión de las competencias políticas. Se trata pues, de un proceso de aprendizaje del que poco depende el capital político previo del que se disponga. Del mismo modo que vimos que era en los partidos políticos donde podía

9 Cfr. Bernard Manin, p. 758, en: "Refaire la démocratie". Rapport n. 3100 (en línea). http://www2.assembleenationale.fr/static/14/institutions/Rapport_groupe_travail_avenir_institutions_T1.pdf, acceso 16 de febrero de 2016. 
acumularse esa especie de capital, ahora vemos que para las tareas políticas de gobierno o de representación institucional, ese capital no puede reconvertirse automáticamente en un repertorio de prácticas concretas de una determinada calidad. Al menos, no más que aquellas de las que pueda servirse cualquier otro ciudadano que no disponga de capital político alguno. En cierto modo, en la descripción de Manin está una parte de la demostración, en la práctica, del profesionalismo que tanto asustaba a los atenienses, y que sostiene las lógicas de funcionamiento del campo político que Weber, Michels y Gaxie nos han ayudado a comprender, prolongándolas en el funcionamiento de las instituciones.

\section{Referencias}

Bourdieu, P. (1988): "Penser la politique", Actes de la recherche en sciences sociales, vol. 71-72, pp. 2-4.

Castoriadis, C. (2005) [1986]: Los dominios del hombre. Las encrucijadas del laberinto, Barcelona, Gedisa.

Castoriadis, C. (2012): La ciudad y las leyes: lo que hace a Grecia, 2, Buenos Aires, Fondo de Cultura Económica.

Gaxie, D. (1977): "Économie des partis et rétributions du militantisme", Revue française de science politique, 27e année, $\mathrm{n}^{\circ} 1$, pp. 123-154.

Landemore, H. (2008): "La démocratie représentative est-elle réellement démocratique?", La Vie des idées (en línea). http://www.laviedesidees.fr/La-democratie-representative-est. html, acceso 14 de abril de 2016.

Lucardie, P. (2014): Democratic Extremism in Theory and Practice. All power to the people, Londres, Routledge.

Manin, B. (1998) [1995]: Los principios del gobierno representativo, Madrid, Alianza Editorial.

Matonti, F., Poupeau, F. (2004/5): "Le capital militant. Essai de définition", Actes de la recherche en sciences sociales, vol. 155, pp. 5-11.

Michels, R. (1914): Les partis politiques. Essai sur les tendances oligarchiques des démocraties, París, Flammarion.

Moreno Pestaña, J.L. (2015): "El sorteo o la socialización del capital político", El Viejo Topo, 327 (abril), 52-59. (en línea)

https://www.academia.edu/11997637/El_sorteo_o_la_socialización_del_capital_político

Sintomer, Y. (2011): Petite histoire de l'expérimentation démocratique. Tirage au sort et politique d'Athènes à nos jours, París, La Découverte.

Weber, M. (1997): [1919], El político y el científico, Madrid, Alianza Editorial. 
